\title{
Cyclic mechanical stability of thermal energy storage media
}

\author{
Henok Hailemariam ${ }^{1, *}$, and Frank Wuttke ${ }^{1}$ \\ ${ }^{1}$ Geomechanics and Geotechnics, Kiel University, Ludewig-Meyn-Straße 10, 24118 Kiel, Germany
}

\begin{abstract}
Closing the gap between supply and demand of energy is one of the biggest challenges of our era. In this aspect, thermal energy storage via borehole thermal energy storage (BTES) and sensible heat storage systems has recently emerged as a practical and encouraging alternative in satisfying the energy requirements of household and industrial applications. The majority of these heat energy storage systems are designed as part of the foundation or sub-structure of buildings with load bearing capabilities, hence their mechanical stability should be carefully studied prior to the design and operation phases of the heat storage system. In this study, the cyclic mechanical performance of a commercial cement-based porous heat storage material is analyzed under different amplitudes of cyclic loading and medium temperatures using a recently developed cyclic thermo-mechanical triaxial device. The results show a significant dependence of the cyclic mechanical behavior of the material, such as in the form of cyclic axial and accumulated plastic strains, on the different thermo-mechanical loading schemes.
\end{abstract}

\section{Introduction}

The field of energy geotechnics has provided many practical solutions in satisfying the worldwide energy demand. One such solution is via clean and renewable energy schemes, such as solid sensible heat storage systems (e.g. cemented media) or seasonal thermal energy storage via borehole thermal energy storage (BTES) systems (e.g. soils). In both applications, heat or cold from solar collectors or other forms of energy is collected, stored for long periods and then used for future industrial or domestic purposes $[1,2]$.

Such systems are usually built at underground levels supporting structures and hence are expected to have load bearing capabilities (Fig. 1). Therefore, adequate studies of their mechanical performance (in the form of static and cyclic mechanical loading), especially at elevated temperatures are essential.

On this regard, in this study, the cyclic mechanical stability of a commercial cement-based porous heat storage material, named Füllbinder L [3], is studied experimentally at different amplitudes of cyclic loading and temperatures (under isothermal conditions) using a cyclic triaxial device. The research was conducted as part of the work of project IGLU [4], which aims at developing solar powered thermal energy storage systems for household applications (Fig. 1).

In addition to the effects of imposed mechanical loads on sensible heat storage systems, the heating and cooling operations of the systems generate extra induced mechanical stresses and strains on the heat storage material, which should also be accounted for during the design and implementation stages of the heat storage setup. These generated mechanical stresses and strains are also dependent on the geometry, loading, boundary and other conditions of the heat storage system and its immediate neighbouring area.

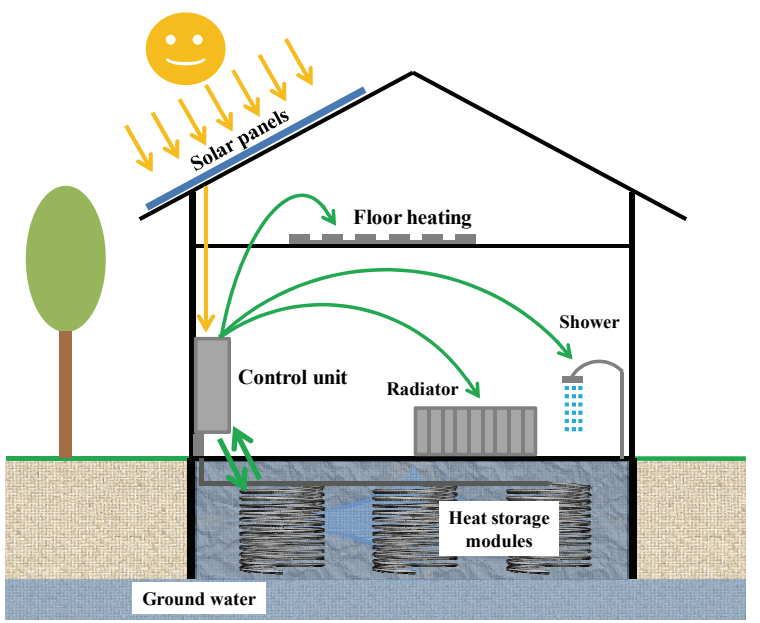

Fig. 1. Schematic representation of the solid sensible heat storage system of project IGLU (with the cement-based heat storage material, Füllbinder L, Fig. 2).

The scope of this research is on the study of the effects of cyclic mechanical loading on the mechanical response and stability of sensible heat storage systems under isothermal conditions, and hence non-isothermal loading effects (heating/cooling operations) are not considered here. However, for comparison purposes, the scales of magnitudes of the mechanical stresses and strains generated from isothermal cyclic mechanical loading (from this study) and non-isothermal heating/cooling loadings (from previous studies) are compared and discussed in section 3.2 of this study.

\footnotetext{
* Corresponding author: henok.hailemariam@ifg.uni-kiel.de
} 


\section{Experimental program}

\subsection{Tested material}

Table 1 shows a list of the obtained physical properties of the Füllbinder L material. The Füllbinder L powder is composed of around $75 \%$ of lime and crashed limestone material, and around $25 \%$ of Portland cement Grade 42.5 by weight, giving the mix its binding properties when mixed with water. The samples were prepared by using a fresh mix of the Füllbinder L powder and water, without the application of any compaction force, and with a selected design water to solids ratio of 0.8 , and then after by storing the newly prepared moulds under water for around 28 days. Storage under water ensures full saturation of the samples and prevents possible cracking due to cement's exothermic hydration processes. A sample Füllbinder L specimen is shown in Fig. 2.

Table 1. Physical properties of the Füllbinder L material.

\begin{tabular}{|c|c|}
\hline Property & Füllbinder $\mathbf{L}^{(1)}$ \\
\hline Bulk density $\left(\mathrm{kg} \mathrm{m}^{-3}\right)$ & 1583 \\
\hline Porosity (-) & 0.543 \\
\hline Specific gravity of solids (-) & 2.28 \\
\hline Thermal conductivity $\left(\mathrm{W} \mathrm{m}^{-1} \mathrm{~K}^{-1}\right)^{(2)}$ & 0.960 \\
\hline Specific heat capacity $\left(\mathrm{J} \mathrm{kg}^{-1} \mathrm{~K}^{-1}\right)^{(2)}$ & 2083.4 \\
\hline Hydraulic conductivity $\left(\times 10^{-8} \mathrm{~m} \mathrm{~s}^{-1}\right)$ & 11.95 \\
\hline Coeff. of thermal expansion $\left(\times 10^{-6} \mathrm{~K}^{-1}\right)$ & 10.7 \\
\hline Modulus of elasticity (GPa) & 1.9 \\
\hline
\end{tabular}

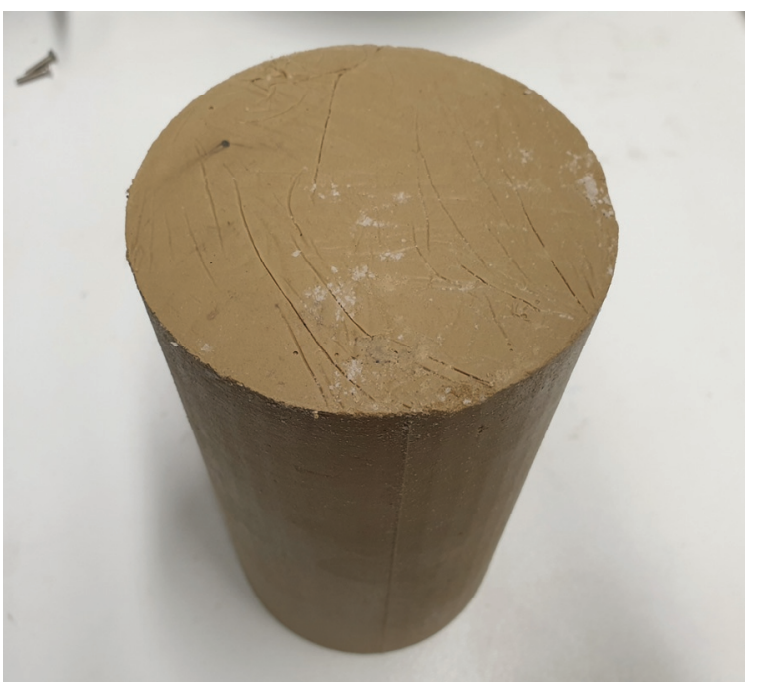

Fig. 2. A sample Füllbinder L specimen.

The effective porosities of the Füllbinder L samples were calculated by preparing separate samples and ovendrying them at $105^{\circ} \mathrm{C}$, and by measuring the dry and saturated bulk weights and the bulk volume of the samples. The effective porosity of the samples, being the reachable fraction of the bulk volume of a specimen which is not occupied by the solid grains, was then calculated as the ratio of the volume of voids to the total volume of the specimen. It should also be noted that the effective porosity of a specimen is different from the total or bulk porosity, which is usually difficult to measure, especially for materials with unreachable or unconnected pore-network pathways. However, for the Füllbinder L material, its hydraulic conductivity is significant enough to ensure that its measured effective porosity is close to its bulk porosity, when the samples are left submerged in water for the given period of time.

To obtain the thermal properties of the samples, transient needle probes of a KD2 Pro device were inserted in to the freshly prepared moulds of the Füllbinder L specimens during the first few days of their preparation, while the material was soft enough to allow the needles to be pushed inside with less resistance. The thermal properties of the material were then measured after 28 days of curing in water as given in Table 1 .

\subsection{Equipments used}

The cyclic mechanical stability of the Füllbinder L samples was analyzed experimentally using a recently developed electromechanical cyclic triaxial testing device (Figs. 3 and 4).

The cyclic testing apparatus consists of a triaxial cell (Fig. 4), a loading machine (with a load cell capacity of $25 \mathrm{kN}$ and capable of applying cyclic deviatoric stresses with frequencies $f$ of up to $5 \mathrm{~Hz}$ ) for applying vertical deviatoric stresses, a dynamic high precision cell pressure system capable of applying cyclic cell pressure to the specimen, two WDC dynamic controllers for the deviatoric stress and the cell pressure, a VPC 10/1000 pore-water/back-pressure application system, a Huber Ministat 125 Pilot ONE heat pump for controlling the temperature of the cell using a circulating fluid (glycol + distilled water), and a PC - data logger system for control and data recording (Fig. 3).

\subsection{Experimental procedure}

The specimens were prepared with a diameter of 100 $\mathrm{mm}$ and a height of $200 \mathrm{~mm}$ making sure that the top and bottom faces were perfectly flat to ensure uniform deviatoric stress distribution. The cyclic loading tests were performed at a cell pressure of $100 \mathrm{kPa}$ and a deviatoric stress $\sigma_{d e v}$ of $150 \mathrm{kPa}$ used as the base load $\sigma_{d e v, b a s e}$ for the cyclic tests, which were conducted with the drainage valves fully open, and without the application of a back-pressure.

The cyclic loading tests were conducted at a frequency $f$ of $0.1 \mathrm{~Hz}$ with deviatoric stress amplitudes $\sigma_{\text {dev,amp }}$ of 10,20 and $30 \mathrm{kPa}$, medium temperatures of 20 and $40^{\circ} \mathrm{C}$, and for a number of cycles $N$ of up to a maximum of around 2200. Prior to the start of the cyclic tests, sufficient temperature stabilization time was allotted to achieve steady state conditions within the samples. The cyclic loading and displacement data was recorded at an acquisition rate of around 0.25 seconds. The mechanical loading (static and cyclic) schemes are diagrammatically depicted as shown in Fig. 5. 

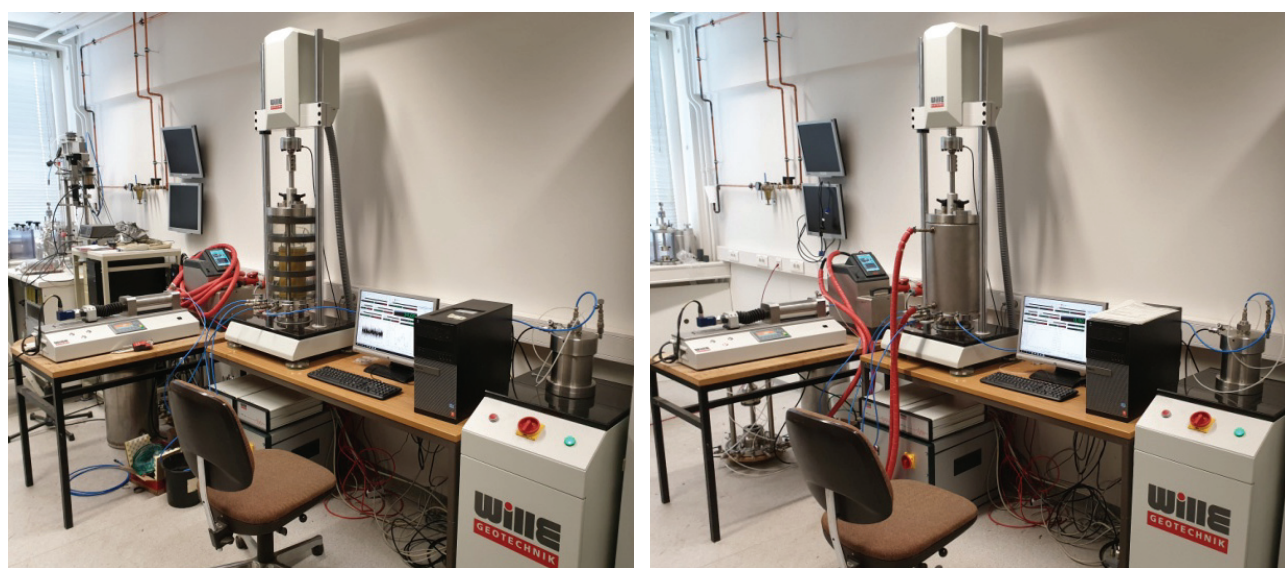

Fig. 3. Cyclic triaxial testing device for: room temperature (left) and elevated temperatures (right).
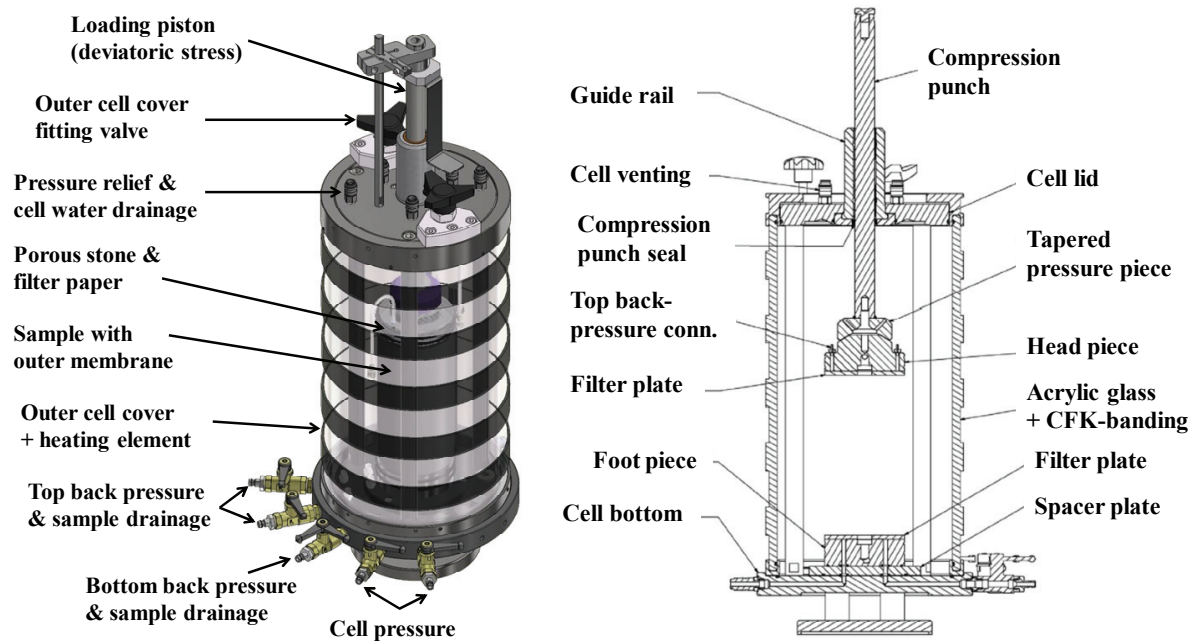

Fig. 4. Schematic representations of the triaxial cell.

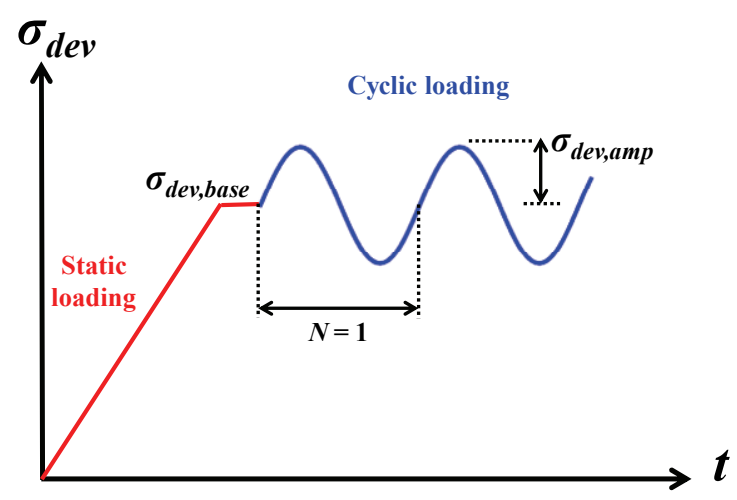

Fig. 5. Schematic representation of the adopted mechanical loading schemes.

\section{Results and discussion}

\subsection{Time plots}

Figure 6 shows the time plot results for the first three cycles of the cyclic loading tests of the Füllbinder L material at room temperature. The plots show a considerable increase in the measured cyclic axial strains $\varepsilon_{c y c}$ of the material with increasing number of cycles $N$, as the stress-strain loops generated due to the application of the cyclic loads are not completely closed.

The increase in the measured $\varepsilon_{c y c}$ of the material leads to irrecoverable strains and the accumulation of plastic strains $\varepsilon_{a c c}$ with each applied cycle. As the adopted frequency $f$ of the cyclic mechanical loading tests in this research is lower than $1 \mathrm{~Hz}$, inertia forces can be neglected and the accumulated axial strains are mainly plastic. Furthermore, the magnitude of $\varepsilon_{a c c}$ of the material is generally the highest during the first cycle, which is usually known as the irregular cycle. 

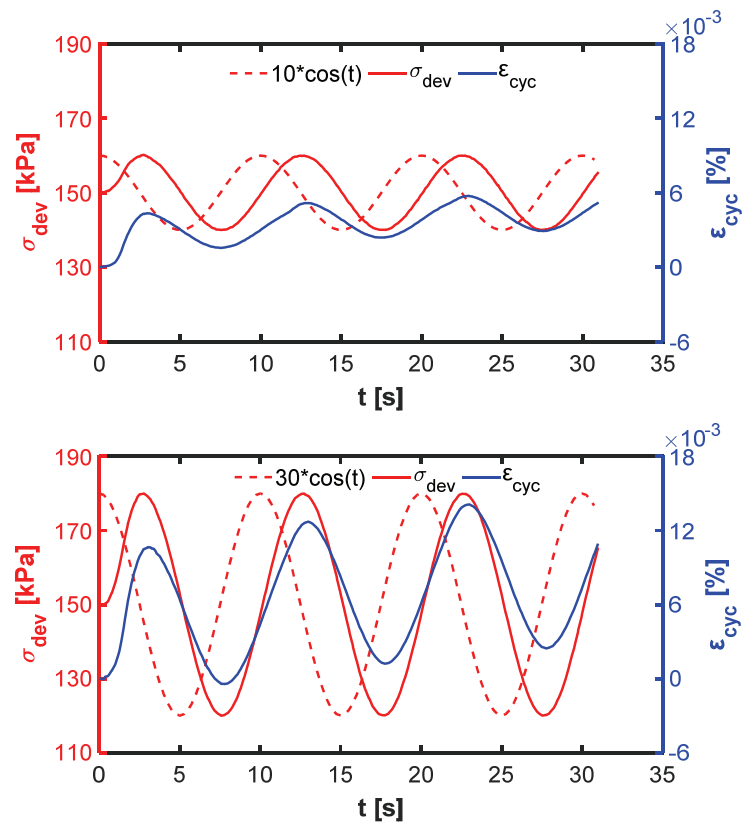

Fig. 6. Cyclic loading time plots of Füllbinder $\mathrm{L}$ for deviatoric stress amplitudes $\sigma_{d e v, a m p}$ of: $10 \mathrm{kPa}$ (top) and $30 \mathrm{kPa}$ (bottom).

\subsection{Cyclic loading test results at different deviatoric stress amplitudes and temperatures}

Figures 7 and 8 show the results of the cyclic loading tests which were conducted at room temperature with deviatoric stress amplitudes $\sigma_{\text {dev, amp }}$ between 10 and 30 $\mathrm{kPa}$, and with $\sigma_{d e v, a m p}=20 \mathrm{kPa}$ at temperatures between 20 and $40^{\circ} \mathrm{C}$. The experimental results show a considerable increase in the measured $\varepsilon_{c y c}$ and hence the accumulation of plastic strains $\varepsilon_{a c c}$ of the Füllbinder $\mathrm{L}$ material with increasing number of cycles $N$ at the studied deviatoric stress amplitudes and temperatures.

The results corroborate with previous finding, where for drained conditions, a cyclic loading can cause plastic strain accumulations at high number of cycles even for small amplitudes of loading, and for un-drained conditions, a cyclic loading with a considerably high amplitude (such as those from an earthquake) can cause

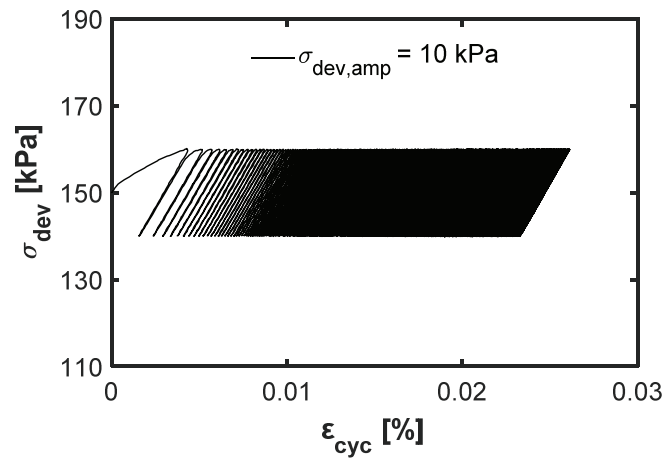

high pore pressure accumulations leading to the liquefaction or the loss of strength of loose granular media [5].

The measured rate of increase of the $\varepsilon_{a c c}$ of the Füllbinder $\mathrm{L}$ material is also directly proportional to the magnitudes of the applied deviatoric stress amplitudes $\sigma_{\text {dev,amp. }}$ (Figs. 7 and 8, left). Moreover, most of the measured $\varepsilon_{a c c}$ of the material occurs within the first 100 cycles, after which the rate of increase of the measured $\varepsilon_{a c c}$ is relatively low. As can be seen in Fig. 8 (right), for the given value of $\sigma_{\text {dev,amp }}$ of $20 \mathrm{kPa}$, an increase in temperature of the Füllbinder L material under lateral confinement (applied cell pressure) decreases its ductility and introduces elastic behavior in its cemented calcite dominated grain-skeleton, which allows for the recovery of a small portion of the cyclic strain $\varepsilon_{c y c}$ of each cycle. This shows that the heated specimen accumulates strains at a slower rate and magnitude than the unheated specimen (at room temperature). As a result, a more stable configuration with a comparatively lower measured $\varepsilon_{a c c}$ is obtained at elevated temperatures.

The lowering of ductility of the Füllbinder L material with an increase in temperature under static (triaxial) loading conditions was also reported in [6]. Hence, the results of cyclic loading tests presented in this study also corroborate the previous finding in the literature with regards to the mechanical loading behavior of cemented porous media. However, to have a more comprehensive behavior of cemented porous media under mechanical loading, detailed future studies are necessary.

The scales of magnitudes of the accumulated plastic mechanical strains generated from the isothermal cyclic mechanical loading results from this study (which are on average of the orders of around $0.03 \%$ after stabilization/shakedown behavior) are generally much higher than those generated during the non-isothermal heating/cooling loadings tests on the same heat storage material as reported in [7] (which are of the orders of around $0.003 \%$ max. after stabilization/shakedown behavior), pointing to the comparatively higher impact of imposed mechanical loads on heat storage structures as opposed to the expected thermal loads.

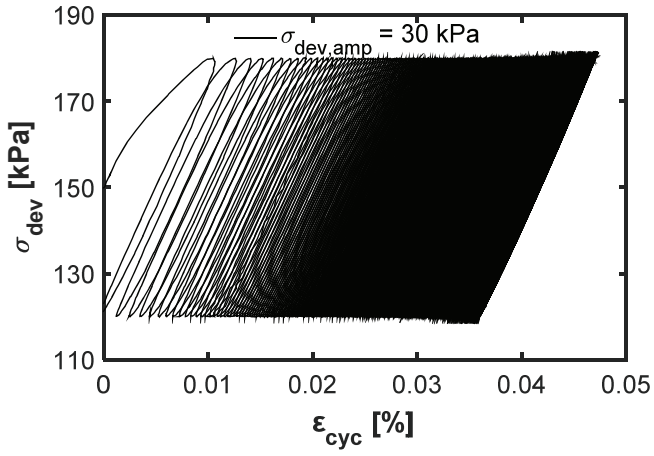

Fig. 7. Room temp. cyclic stress - strain plots for Füllbinder L at deviatoric stress amplitudes of: $10 \mathrm{kPa}$ (left) and $30 \mathrm{kPa}$ (right). 

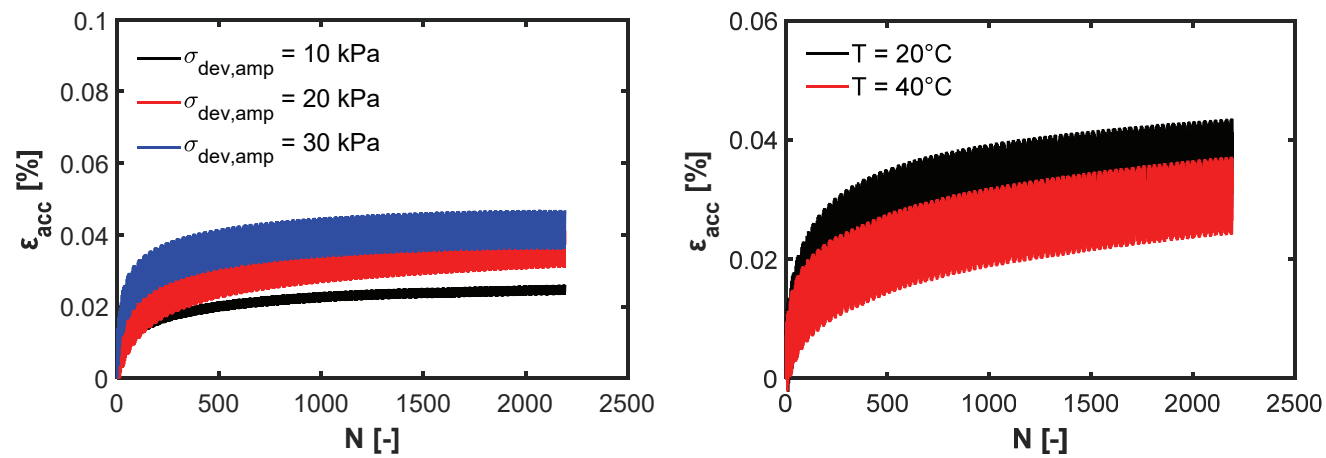

Fig. 8. Accumulated plastic strain vs. number of cycles plots for: different deviatoric stress amplitudes (left) and temperatures (right).

\section{Conclusions}

Analyzing the mechanical stability (in the forms of static and cyclic loading) of sensible heat storage media prior to their design and operation is vital, as such systems are typically implemented at or below ground level with load bearing capabilities and providing support to structures. In particular, for heat storage systems subjected to cyclic mechanical loading, accurate estimate of the accumulated plastic strains of the heat storage media ensures that future serviceability failures are avoided. In this study, the cyclic mechanical stability of a commercial cement base heat storage material was experimentally studied using a recently developed cyclic electromechanical triaxial device. The findings indicated a considerable increase in the measured axial cyclic and accumulated plastic strains of the material with increasing number of cycles, and also a significant dependence on the amplitude of the applied cyclic loading and the medium temperature.

The authors gratefully acknowledge the financial support provided by the German Federal Ministry for Economic Affairs and Energy (BMWi) under Grant numbers 0325547B (Project IGLU) and 03ET6122A (Project ANGUS II). We would also like to thank APS Antriebs-, Prüf- und Steuertechnik GmbH, Rosdorf, Germany, for kindly providing us with the raw images for the schematic diagrams of the triaxial cell shown in Fig. 4.

\section{References}

1. D. Laing, W-D. Steinmann, R. Tamme, C. Richter, Solid media thermal storage for parabolic trough power plants. Solar Energy 80, 10 (2006)

2. D. Laing, C. Bahl, T. Bauer, M. Fiss, N. Breidenbach, M. Hempel, High-temperature solidmedia thermal energy storage for solar thermal power plants. Proceedings of the IEEE 100, 2 (2012)

3. Schwenk Zement KG, Füllbinder L Technisches Merkblatt (2016)

4. S. Bauer, C. Beyer, A. Dahmke, H. Hailemariam, K. Meier zu Beerentrup, J. Nordbeck, F. Wuttke, Untersuchung, Modellierung und Bewertung eines intelligenten geothermischen Langzeit wärmespeichers mit umweltneutralem Verhalten $I G L U$ : Schlussbericht zum Verbundvorhaben (2018)

5. A. Sawicki, W. Swidzinski, Mechanics of a sandy subsoil subjected to cyclic loadings. International Journal for Numerical and Analytical Methods in Geomechanics 13 (1989)

6. H. Hailemariam, D. Schwindrofska, F. Wuttke, Mechanical stability of cemented porous heat storage media (XVI Pan American Conference on Soil Mechanics and Geotechnical Engineering, IOS Press, 2019)

7. H. Hailemariam, F. Wuttke, Thermal cyclic stability analysis of porous heat storage materials (Energy Geotechnics, SEG 2018, Springer Series in Geomechanics and Geoengineering, Springer, Cham, Switzerland, 2019) 